\title{
PREVALENCE OF ANTIMICROBIAL RESISTANCE (AMR) SALMONELLA SPP. AND ESCHERICHIA COLIISOLATED FROM BROILERS IN EAST COAST MALAYSIA
}

Shamsaldeen Ibrahim $^{1,2}$, Loh Wei Hoong ${ }^{3}$, Yip Lai Siong ${ }^{3}$ Zaharuddin Mustapha $^{4}$, Che Wan Salma Che Wan Zalati ${ }^{1}$, Erkihun Aklilu', Maizan Mohamad', Nor Fadhilah Kamaruzzaman ${ }^{1^{*}}$

${ }^{1}$ Faculty of Veterinary Medicine, University Malaysia Kelantan, 16100 Pengkalan Chepa, Kelantan, Malaysia

${ }^{2}$ Faculty of Veterinary Science, University of Nyala, PO Box 155 | South Darfur State, Nyala, Mousseh district, south of the city, Sudan.

${ }^{3}$ Rhone Ma Malaysia Sdn. Bhd., Lot 18A \& 18B, Jalan 241, Seksyen 51a , 46100 Petaling Jaya, Selangor

4Department of Veterinary Services Pahang, Jalan Sri Kemunting 2, 25100 Kuantan, Pahang.

Corresponding author: norfadhilah@umk.edu.my,+6097717330 


\section{Abstract:}

Salmonella species (spp) and Escherichia coli (E. coli) are the most common infectious pathogens in poultry. Antimicrobials were given either for the treatment or growth promoters that can increase the possibility of emergence of bacterial resistance towards antimicrobials. The aim of this study was to determine the prevalence of antimicrobial resistant (AMR) Salmonella spp and $E$. coli isolated from a sample of broiler farms in East Coast Malaysia from 2018-2019. A total of 384 cloacal swabs were collected from broilers farms in Kelantan, Terengganu, and Pahang. The bacteria were isolated and confirmed by bacteriological and serological methods. Following that, confirmed isolates were subjected to antimicrobial susceptibility test. Salmonella spp and $E$. coli were recovered from the cloacal swabs samples with the overall prevalence of $6.5 \%$ and $51.8 \%$ respectively. In Kelantan, Terengganu and Pahang, the prevalence of Salmonella spp were 7\%,6.5\% and 5.8\% respectively, while the prevalence for E. coli were $50 \%, 48.3 \%$ and $58 \%$ respectively. Salmonella spp and E. coli displayed resistance towards the following antimicrobials: erythromycin (100\% for both pathogens), chloramphenicol $(76.2 \%, 84.5 \%)$, tetracycline $(62 \%$, $94.6 \%$, ampicillin (47.7\%, 87\%), sulfamethoxazole/trimethoprim (42.9\%, 83.3\%), ciprofloxacin (4.8\%, 23.8\%), nalidixic acid (9.6\%, 60.7\%), streptomycin (19\%,66\%), and kanamycin $(28.6 \%, 57 \%)$, cephalotin (0\%, 11\%), gentamicin $(0 \%, 20.2 \%)$ respectively. No resistance were recorded towards colistin for both pathogens. Multidrug resistance (MDR) was recorded in $82 \%$ of Salmonella spp and $100 \%$ of $E$. coli. These findings demonstrate the high prevalence of MDR Salmonella spp. and E. coli in broiler farms in East coast Malaysia. This could be attributed to the excessive use of antimicrobial agents by the poultry farm owners. Enhanced control measures and a strong monitoring system should be urgently implemented to reduce the emergence of antimicrobial resistance that is harmful to public health.

Keywords; Antimicrobial resistance, Salmonella species, E.coli, Broiler chickens, Malaysia 


\section{INTRODUCTION}

The poultry industry is the primary agricultural sector in Malaysia which contributes $62.9 \%$ from the total GDP in the animal farming industry (Amna et al., 2020). It has transformed with increasing in the number of production as well as increasing number of integrators. Malaysians consume approximately 1.8 million chicken and 2.8 million eggs daily, which is translated for annual consumption of 31 $\mathrm{kg}$ of meat and $16.6 \mathrm{~kg}$ of eggs per capita. This consumption is considered among the highest in the world, due to the large Muslim population and higher price of other protein sources such as beef and mutton (Orissa International Sdn Bhd, 2017). In Peninsular Malaysia, the supply is by approximately 3,200 broiler farms which includes contract and independent farmers, as well as large vertically integrated farms. Though the industry is expanding, the sector still faces many challenges, which include infectious disease outbreak of avian salmonellosis and colibacillosis (Chuah et al., 2018; Daud et al., 2014).

Avian salmonellosis can be caused by intestinal colonization and invasion by Salmonella serovars resulting in enteritis, septicemia, and mortality in animal. Some Salmonella serovars, particularly Salmonella Typhimurium and Salmonella Enteritidis, can persist in the digestive tracts of chickens (Huang et al., 2009). Salmonellosis is caused by non-typhoidal Salmonella and typically characterised by gastroenteritis syndrome in human (Antunes et al., 2016). Avian colibacillosis is a significant infectious disease caused by pathogenic $E$. coli strains and causes massive economic losses to the poultry industry due to high morbidity, mortality, and cost of treatment and prevention (Kim et al., 2020). The condition is characterised by respiratory infection, yolk sac infection, coli granuloma, enteritis, cellulitis omphalitis, swollen head syndrome, septicemia, polyserositis, and salpingitis (Kabir, 2010). Transmission of Salmonella and $E$. coli to humans could occur through the consumption of contaminated poultry and handling of the raw poultry (Chuah et al., 2018).

Antimicrobials are used widely for treatment, prevention of the infectious disease in livestock, and excessive use and misuse of antimicrobials, in part were associated with increasing rates of antimicrobial resistance among pathogens isolated from animal. There is growing concerned that widespread antimicrobial use has led to the 
emergence of some organisms resistant to most or all antimicrobials (Teillant \& Laxminarayan, 2015). Antimicrobial resistance present in bacteria from production animals may lead to therapy failure and economic losses for the farmer, and transferring of resistance to potential human pathogenic bacteria, and likewise causing treatment difficulties (van den Bogaard \& Stobberingh, 1999). Antimicrobial resistance is a big challenge to the Malaysian public health. Increasing cases of treatment failure in human and animal were reported in recent years showed that the pathogen do not respond to the antimicrobials administered for the treatment (Alreshidi, M.A et al., 2018).

Despite the data available for the antimicrobial resistance in pathogen isolated in poultry in Malaysia, we find very limited data on the prevalence of antimicrobial resistance Salmonella spp and E. coli in the poultry farm in East Coast Malaysia; Kelantan, Terengganu and Pahang (Jajere et al., 2019). Thus the aim of the present study was to determine the prevalence of AMR Salmonella spp and E.coli isolated from broiler farms in these three states. 


\section{MATERIALS AND METHODS}

\section{Ethical statement}

The current study was conducted at Zoonotic laboratory, Faculty of Veterinary Medicine, Universiti Malaysia Kelantan. The study protocols, procedures, and consent form were approved by the Institutional Animal Care and Use Committee of Universiti Malaysia Kelantan (UMK/FPV/ACUE/PG/2/2019).

\section{Sample size determination and sampling method}

The sample size was determined by using StatCalc from Epi-Info (7) using a formula based on Thrusfield (2007). The calculation was based on the assumption of an expected prevalence of $50 \%$ for E.coli based on the previous literature (Jamnah et al., 2014).

$$
\mathrm{n}=\frac{1.962 \text { Pexp }(1-\text { Pexp })}{\mathrm{d} 2}
$$

Where, $\mathrm{n}=$ required sample size

$1.96=95 \%$ level of confidence

$\mathrm{P} \exp =$ exposed prevalence

$d=$ desired absolute decision

Cloacal swabs were obtained from broilers from 30 different farms in Kelantan, Terengganu, and Pahang. Farms were selected based on the list of broiler farms provided by the Department of Veterinary Services, Malaysia. Farm selection were performed by the multistage random selection method. Cloacal swabs were collected aseptically using sterile swabs with Ames transport media. Following sample collection, the samples were immediately transported back to the laboratory under cold storage for further processing.

\section{Isolation and identification of bacteria}

Prior to bacteria isolation, pre-enrichment was performed by inoculating the swabs into buffered peptone water (BPW; Oxoid, UK) followed by incubation at $37^{\circ} \mathrm{C}$ for 24 hours. For E. coli isolation, the enriched BPW was streaked on MacConkey agar 
plates (MAC; Oxoid, UK) and incubated aerobically for 24 hours at $37^{\circ} \mathrm{C}$. Suspected lactose fermentative $E$. coli colonies were sub-cultured on eosin methylene blue agar (EMB; oxoid, UK) for another 24 hours at $37^{\circ} \mathrm{C}$. Suspected E.coli which displayed green metallic shine colonies were further subjected to biochemical testing. Colonies that exhibited acid slant, acid butt, and no $\mathrm{H}_{2} \mathrm{~S}$ production on triple sugar iron, indole and decarboxylase positive, regardless of motility, were considered to be $E$. coli and were subcultured and stored in glycerol stock and kept at $-80^{\circ} \mathrm{C}$ until ready to be used.

For Salmonella isolation, $0.1 \mathrm{~mL}$ of BPW mixture were inoculated in Rappaport - Vassiliadis Soya Pepton Broth (RVS; Oxoid, UK) at $42^{\circ} \mathrm{C}$ for 24 hours for selective enrichment. Following that, the RVS mixture was streaked in xylose-lysinedesoxycholate agar (XLD; Oxoid, UK ) and incubated aerobically for 24 hours at $37^{\circ} \mathrm{C}$. After $24 \mathrm{hrs}$, the plate was examined for the presence of suspected Salmonella spp. The suspected colonies were subjected to biochemical test followed by latex agglutination test using the commercial available polyvalent antisera (Oxoid Salmonella test kit DR1108A) to screen for Salmonella flagellar antigen. Briefly, a loop full of suspected colonies were emulsified with one drop of $0.85 \%$ sodium chloride on the reaction card to produce the smooth suspension. Then a drop of Salmonella latex reagent was added and mixed with the organism suspension with the clean mixing stick. Salmonella isolates will cause an agglutination in the reaction.

\section{Antimicrobial susceptibility test}

The antimicrobial susceptibility for all isolates were determined through the standard antimicrobial disk diffusion test protocol by the Clinical and Laboratory Standard Institute (CLSI, 2016). The following antimicrobial commercial disc from Oxoid, UK were used in this study: tetracycline(TE; $30 \mu \mathrm{g})$, chloramphenicol (C; 30

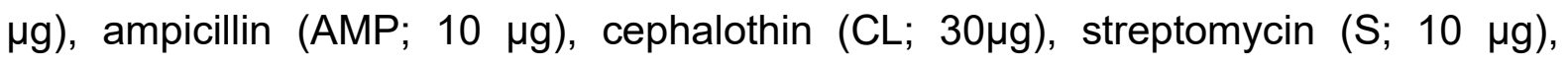
gentamicin ( $\mathrm{CN} ; 10 \mu \mathrm{g}$ ), sulfamethoxazole/trimethoprim (SXT; $25 \mu \mathrm{g}$ ), nalidixic acid (NA;30 $\mu \mathrm{g}$ ), ciprofloxacin (5 $\mu \mathrm{g})$, erythromycin(E; $15 \mu \mathrm{g})$, kanamycin (K; $30 \mu \mathrm{g})$ and Clostine sulphate $(\mathrm{CT} ; 10 \mu \mathrm{g})$. All selected antimicrobials are commonly used for the treatment of infections associated with E. coli, and Salmonella based on the recommendation by World Organisation for Animal Health (OIE, 2014). Briefly, 0.5 McFarland bacterial suspension was prepared and plated on the agar surface. Six 
paper discs were placed onto each agar plate using a dispenser. The plate was incubated at $37^{\circ} \mathrm{C}$ for 18 hours. The resulting zones of inhibition (ZOI) was measured in millimetre using a vernier caliper and measurements were rounded off to the nearest whole number. The antimicrobial sensitivity profiles of the isolates were determined following the zone of inihibition diameter breakpoints and interpretative categories (susceptible, intermediate or resistant) for Enterobacteriaceae as recommended by CLSI (CLSI,2016) (Table 1).

\section{Determination of multiple antimicrobial resistance (MAR) indexes}

MAR was calculated as reported by Christopher and Ali (2013) as follows:

$$
\text { MAR index }=\frac{\text { Number of antimicrobials to which the isolate showed resistance }}{\text { Number of total antibiotics exposed to the isolate }}
$$

Results were interpreted according to the criteria of Nandi \& Mandal: MAR index $\leq 0.2$ was considered low risk, while $\geq 0.2$ indicated a high risk of antimicrobial contamination (Akande et al., 2019)

\section{Statistical analysis}

The results were analyzed statistically using the Graph Pad Prism version 8. The level of significance was determined at $95 \%$ confidence level and $p<0.05$. 


\section{RESULTS}

\section{Prevalence of Salmonella spp and E. coli in broiler poultry farms in Kelantan,} Terengganu and Pahang.

Of 384 samples, a total of 25 Salmonella spp. and $199 \mathrm{E}$. coli were isolated with the overall prevalence of $6.6 \%$ and $51.8 \%$, respectively. In Kelantan, Terengganu and Pahang, the prevalence of Salmonella spp were $7 \%, 6.5 \%$ and $5.8 \%$ respectively, while the prevalence for $E$. coli were $50 \%, 48.3 \%$ and $58 \%$ respectively. Table 2 summarizes the results for the prevalence and distribution of Salmonella spp. and $E$. coli isolated from broilers in the three state.

\section{Salmonella and E. coli susceptibility towards antimicrobial tested}

Overall Salmonella and E. coli susceptibility towards antimicrobial tested

To determine Salmonella spp. and E. coli isolates susceptibility towards selected antimicrobials, antimicrobial susceptibility test were performed using disc diffusion methods. Salmonella spp and E. coli displayed resistance towards the following antimicrobials; erythromycin (100\% for both pathogen), chloramphenicol $(76.2 \%, 84.5 \%)$, tetracycline (62\%, 94.6\%), ampicillin $(47.7 \%$, $87 \%)$, sulfamethoxazole/trimethoprim $(42.9 \%, 83.3 \%)$, ciprofloxacin $(4.8 \%$, $23.8 \%)$, nalidixic acid $(9.6 \%, 60.7 \%)$, streptomycin (19\%,66\%), and kanamycin (28.6\%,57\%), cephalotin $(0 \%, 11 \%)$, gentamicin $(0 \%, 20.2 \%)$ respectively. All Salmonella and $E$. coli isolates were sensitive towards colistin antimicrobial. Table 3 summarises Salmonella and E. coli towards all antimicrobials tested.

\section{Distribution of antimicrobial resistance in Kelantan, Terengganu and Pahang}

In Kelantan, $>50 \%$ Salmonella spp recorded resistance towards tetracycline, chloramphenicol, ampicillin and erythromycin. While $>50 \%$ E. coli recorded resistance towards all antimicrobials tested except for ciprofloxacin, cephalothin and colistin sulphate. 
In Terengganu $>50 \%$ Salmonella spp recorded resistance towards tetracycline, chloramphenicol, sulfamethoxacole/trimethophrim and erythromycin. While $>50 \%$ E. coli isolates demonstrated resistance towards almost all antimicrobials except cephalotin and colistin sulphate.

Finally in Pahang, $>50 \%$ Salmonella spp recorded resistance towards tetracycline, chloramphenicol, ampicillin and erythromycin. While $>50 \%$ E. coli isolates demonstrated resistance towards almost all antimicrobials except cephalotin and colistin. In summary, the highest resistance for Salmonella and E. coli for all three states were towards tetracycline, chloramphenicol and erythromycin. Table 4 summarised the distribution of AMR in Kelantan, Terengganu and Pahang.

\section{Salmonella spp and E. coli multi drug resistance (MDR) profile}

The MDR profile for Salmonella spp and E. coli were also tabulated. A total of $81 \%$ of Salmonella spp isolates showed multidrug resistance profile (resistance to $>1$ antimicrobial). This includes $4.8 \%$ isolates that were resistance to six, seven and eight antimicrobials, $14.2 \%$ to five antimicrobials, $42.8 \%$ to four antimicrobials and $9.5 \%$ to three antimicrobials, respectively. The most predominant MDR profile for Salmonella spp. were TE-C-AMP-E, TE-C-SXTE, C-AMP-K-E and C-AMP-SXT-E.

In parallel, $5.9 \%$ of $E$. coli were resistant to ten antimicrobials, $10.7 \%$ to nine antimicrobials, $21.4 \%$ to eight antimicrobials, $20.2 \%$ to seven antimicrobials, $17.2 \%$ to six antimicrobials, $12.5 \%$ to five antimicrobials, $6.5 \%$ to four antimicrobials and $3.5 \%$ to three antimicrobials, respectively. MDR profile $E$. coli isolates showed varieties of AMR profile, where 56 different MDR profile were recorded. The most predominant antibiotype were TE-C-AMP-S-SXT-NAK-E, TE-C-AMP-S-SXT-NA-E and TE-C-SXT-NA-E-CIP. Table 4 summarises the MDR profile for Salmonella spp and E. coli. 


\section{Multiple Antimicrobial Resistance (MAR) Index}

Multiple antimicrobial resistance index is helpful in analyzing health risk, as well as to check the extent of antimicrobial resistance. The MAR index was calculated for both Salmonella and E. coli isolates. The analysis showed $71 \%$ of Salmonella isolates have MAR $>0.2$, while $96 \%$ E. coli isolates showed MAR index $>0.2$ (Table 5), suggested that the isolates originated from the high-risk source of contamination where the antimicrobials are commonly used.

\section{DISCUSSIONS}

Increasing AMR cases in human, in part, has been correlated with transmission of the pathogen from animal to human. Here we found that Salmonella and E. coli isolated from broilers in East coast Malaysia displayed multi drug resistance towards commonly used antimicrobials used in animal. We also find that majority of the isolated Salmonella and E. coli has MAR index>0.2.

Salmonella spp and E. coli are the predominant bacteria associated with bacterial infection in poultry. These organisms are known to result in serious problems to poultry health leading to mortality, reduced production and increased expense in the cost of prevention and treatment of the disease. Broad diversity of antimicrobials are used to raise poultry in most countries, mostly through the oral route, to prevent and to treat disease, but also to enhance growth and productivity (Nhung et al., 2017). The findings of our study is in agreement with a study conducted in Selangor, Malaysia that reported a high prevalence rate of $E$. coli $(60 \%)$ compared to only $7.5 \%$ of Salmonella spp. isolated from the same samples (Geidam, 2012). Another study reported the prevalence of Salmonella isolated from village chicken in Malaysia was 2.5\% (Jajere et al., 2019). The low prevalence of Salmonella isolated from poultry was also reported in other countries such as Nigeria (2\%) and European countries (Gonçalves-Tenório et al., 2018; Chinasa. et al., 2019). It is interesting to note that the same trend does not appear to be so in Bangladesh as a study showed a high prevalence (48\%) of Salmonella isolated from poultry (Islam et al., 2017). 
Antimicrobial resistance in chickens is a common problem in Malaysia and other developing countries due to the practice antimicrobials used as feed additives and prophylactic treatment of infectious diseases. Our study found that $100 \%$ Salmonella and $E$. coli resistance towards erythromycin antimicrobial, and this finding is in agreement with another study conducted in Bangladesh that reports the same trend of resistance (Islam et al., 2017). Our study also found high prevalence of multidrug resistance Salmonella and E. coli isolates which are in agreement by previous study conducted in Malaysia (Geidam, 2012). These findings provide evidence of the emergence of antimicrobials resistance of Salmonella spp and E. coli among poultry farm in Malaysia. It is interesting to note that all Salmonella and E. coli isolates were susceptible to colistin, though a recent study conducted in the same region detected MCR-1 gene which encoded colistin resistant in E. coli isolated in raw chicken meat in Kelantan, Malaysia (Aklilu \& Raman, 2020). It is important to note that the study conducted by Aklilu and Raman were using molecular biology method that are known to be more sensitive compared to the disc diffusion method.

In conclusion, this finding indicated the high prevalence of multi- drugs resistant Salmonella spp. and E.coli in poultry farms in East Coast Malaysia and this, in part, could be attributed to the excessive use of antimicrobial agents by poultry farm owner and these potentially harmful to public health. Control measures and strong monitoring system should be urgently advocated and implemented in Malaysia to reduce the emergence of AMR. Also, further research on alternative to antimicrobials, good animal husbandry practice and biosecurity should be encouraged to replace the application of existing antimicrobials in animal health.

\section{ACKNOWLEDGMENT}

This work was supported by Rhone Ma Malaysia Sdn. Bhd grant number R/RMA/A06.00/00686A/002/2018/000541. The author express their appreciation to FPV, UMK Kelantan and Department Veterinary services, Malaysia for facilities to conduct this work. The author also would like to acknowledge the broiler farms owner for their assistance during the sampling procedures 


\section{AUTHOR CONTRIBUTIONS}

S. I. S. performed the experiment and wrote the manuscript. LWH, YLS. ZM helped during the sampling process, CWSCWZ helped during the bacterial isolation, EA, MM and NFK supervise the work and wrote the manuscript. We thank Dr. Raymond Choo for helping in proofreading of the manuscript.

\section{CONFLICT OF INTEREST}

No conflict of interest 


\section{REFERENCES}

1. Akande, E., Abodunrin, T., Oladejo, B., \& Oladunmoye, M. (2019). Antibiogram and plasmid profiling of resistance bacteria isolated from the blood of Hepatitis $C$ Virus positive individuals. Journal of Microbiology \& Experimentation, 7(3), 156165.

2. Aklilu, E., \& Raman, K. (2020). MCR-1 Gene Encoded Colistin-Resistant Escherichia coli in Raw Chicken Meat and Bean Sprouts in Malaysia. International Journal of Microbiology. https://doi.org/10.1155/2020/8853582

3. Alreshidi, M.A., Neela, V, Alsharari, A.S., Hamat, R.A., Alsalamah, A.A., Atshan, S.S., Alzoghaibi, O., and Shamsudin, M. N. (2017). Molecular typing and antibiotic resistance patterns of methicillin-resistant Staphylococcus aureus isolates from clinical samples in Malaysia : An update. Tropical Biomedicine, 34(1), 1-6.

4. Amna, N., Mohammad, A., \& Rosali, M. H. (2020). The Development and Future Direction of Malaysia 's Livestock Industry. 1-7. Retrieved from https://ap.fftc.org.tw

5. Antunes, P., Mourão, J., Campos, J., \& Peixe, L. (2016). Salmonellosis: The role of poultry meat. Clinical Microbiology and Infection, 22(2), 110-121.

6. Chuah, L. O., Shamila Syuhada, A. K., Mohamad Suhaimi, I., Farah Hanim, T., \& Rusul, G. (2018). Data on antibiogram and resistance genes harboured by Salmonella strains and their Pulsed-field gel electrophoresis clusters. Data in Brief, 17, 698-702.

7. Clinical, L. S. A. I. (2016). Clinical and Laboratory Standards Institute: Performance Standards for Antimicrobial Susceptibility Testing Supplement M100S.

8. Daud, N., Hatin, N., Abba, Y., Paan, F., Kyaw, T., Khiang, A., Jesse, F., Mohammed, K., Adamu, L., \& Tijjani, A. (2014). An Outbreak of Colibacillosis in a Broiler Farm. Journal of Veterinary Advances, 4(7), 648.

9. Geidam, Y. (2012). High Prevalence of Multi-drug Resistant Bacteria in Selected Poultry Farms in. Aisan Journal of Animal and Veterinary Advances, 7(9), 891897.

10. Gonçalves-Tenório, A., Nunes Silva, B., Rodrigues, V., Cadavez, V., \& Gonzales-Barron, U. (2018). Prevalence of pathogens in poultry meat: A meta- 
analysis of European published surveys. Foods, 7(5).

11. Huang, T.-M., Lin, T. L., \& Wu, C. C. (2009). Antimicrobial Susceptibility and Resistance of Chicken Escherichia Coli, Salmonella spp., and Pasteurella Multocida Isolates. Avian Diseases, 53(1), 89-93. https://doi.org/10.1637/8268021608-reg. 1

12. Islam, J., Ahmed, T., \& Hasan, K. (2017). Isolation and identification of Salmonella spp. from broiler and their antibiogram study in Sylhet, Bangladesh. Journal of Applied Biology \& Biotechnology, 4(03), 46-51.

13. Jajere, S. M., Hassan, L., Aziz, S. A., Zakaria, Z., Abu, J., Nordin, F., \& Faiz, N. M. (2019). Salmonella in native "village " chickens (Gallus domesticus ): prevalence and risk factors from farms in South-Central Peninsular Malaysia. Poultry Science, 98(5961), 5970.

14. Jamnah, O., Faizal, H., Chandrawathani, P., Premaalatha, B., Rozita, L., \& Ramlan, M. (2014). Malaysian journal of veterinary research eperythrozoonosis ( mycoplasma sp .) In malaysian pangolin. 5(June), 65-68.

15. Jindal, H. M., Ramanathan, B., Le, C. F., Gudimella, R., Razali, R., Manikam, R., \& Sekaran, S. D. (2018). Comparative genomic analysis of ten clinical Streptococcus pneumoniae collected from a Malaysian hospital reveal 31 new unique drug-resistant SNPs using whole genome sequencing. Journal of Biomedical Science, 1-14.

16. Kabir, S. M. L. (2010). Avian Colibacillosis and Salmonellosis : A Closer Look at Epidemiology , Pathogenesis, Diagnosis, Control and Public Health Concerns. 89-114.

17. Kim, Y. Bin, Yoon, M. Y., Ha, J. S., Seo, K. W., Noh, E. B., Son, S. H., \& Lee, Y. J. (2020). Molecular characterization of avian pathogenic Escherichia coli from broiler chickens with colibacillosis. Poultry Science, 99(2), 1088-1095.

18. Mkk, F., Rashid, S. S., Mhm, N., Zaidul, I. S. M., Baharudin, R., \& Nor, A. (2018). A clinical update on Antibiotic Resistance Gram-negative bacteria in Malaysia- a review. Journal of International Pharmaceutical Research, 45, 270-283.

19. Nhung, N. T., Chansiripornchai, N., \& Carrique-Mas, J. J. (2017). Antimicrobial Resistance in Bacterial Poultry Pathogens: A Review. Frontiers in Veterinary Science, 4(August), 1-17.

20. Orissa International Pte. Ltd. (2017, March ). Poultry Sector in South East Asia. In lowa Economic Development Authority. Retrieved from 
www.iowaeconomicdevelopment.com

21. Teillant, A., \& Laxminarayan, R. (2015). Economics of Antibiotic Use in U . S . Swine and Poultry Production. Choices, 30(1), 1-11.

22. Thrusfield, M. (2007). Sample size determination. In Veterinary Epidemiology.

23. Chinasa, V., Eleazar, E., Scholastica, N., \& Ike, A. C. (2019). Isolation, Identification and Antibiogram of Salmonella from Cloacal Swabs of Isolation, Identification and Antibiogram of Salmonella from Cloacal Swabs of Free Range Poultry in Nsukka, Nigeria. Journal of Advcances Microbiology, 17(1), 1-9.

24. van den Bogaard, A. E., \& Stobberingh, E. E. (1999). Antibiotic Usage in Animals. Drugs, 58(4), 589-607. 
Table 1: Zone diameter interpretative breakpoints for the tested antimicrobials (CLSI,2016)

Zone of inhibition (mm)

Antimicrobial Disc code \& content Sensitive Intermediate Resistant

$(\mu g)$

\begin{tabular}{lcccc} 
Penicillin & 10 units & $\geq 29$ & - & $\leq 28$ \\
Ampicillin & AMP (10) & 14 & $12-14$ & 11 \\
Oxacillin & OX (1) & $\geq 18$ & - & $\leq 17$ \\
Tetracycline & TE (30) & $\geq 19$ & $15-18$ & $\leq 14$ \\
Gentamicin & CN (10) & $\geq 15$ & $13-14$ & $\leq 12$ \\
Erythromycin & E (15) & $\geq 23$ & $14-22$ & $\leq 13$ \\
Chloramphenicol & C (30) & $\geq 18$ & $13-17$ & $\leq 12$ \\
Ciprofloxacin & CIP (5) & $\geq 21$ & $16-20$ & $\leq 20$ \\
Kanamycin & K (30) & $\geq 18$ & $14-17$ & $\leq 13$ \\
Nalidixic acid & NA (3) & $\geq 19$ & $14-18$ & $\leq 13$ \\
Sulfamethoxazole & SXT (25) & 16 & $11-15$ & 10 \\
-trimethoprim & & & & \\
Streptomycin & S (10) & 21 & $15-20$ & 14 \\
Vancomycin & VA (30) & $\geq 17$ & $15-16$ & $\leq 14$ \\
Cephalexin & CF (30) & $\geq 18$ & $15-17$ & $\leq 14$ \\
Colistin sulphate & CT (10) & $\geq 11$ & - & $\leq 10$ \\
\hline
\end{tabular}


Table 2. Prevalence and distribution of Salmonella spp. and E. coli isolated from broiler in Kelantan, Terengganu dan Pahang

\begin{tabular}{|c|c|c|c|}
\hline State/ Locality & $\begin{array}{c}\text { No. of collected } \\
\text { samples }\end{array}$ & $\begin{array}{l}\text { Prevalence of } \\
\text { Salmonella spp }\end{array}$ & $\begin{array}{c}\text { Prevalence of } \\
\text { E. coli }\end{array}$ \\
\hline \multicolumn{4}{|l|}{ Kelantan } \\
\hline Machang & 40 & $0 \%$ & $50 \%$ \\
\hline Bachok & 40 & $15 \%$ & $45 \%$ \\
\hline Tumpat & 40 & $12.5 \%$ & $62.5 \%$ \\
\hline Pasir Mas & 40 & $7.5 \%$ & $37.5 \%$ \\
\hline Jeli & 40 & $0 \%$ & $55 \%$ \\
\hline total & 200 & $7 \%$ & $50 \%$ \\
\hline \multicolumn{4}{|l|}{ Terengganu } \\
\hline Marang & 30 & $0 \%$ & $33.3 \%$ \\
\hline Hulu Terengganu & 30 & $13.3 \%$ & $63.3 \%$ \\
\hline total & 60 & $6.5 \%$ & $48.3 \%$ \\
\hline \multicolumn{4}{|l|}{ Pahang } \\
\hline Kuantan & 32 & $0 \%$ & $65.6 \%$ \\
\hline Pekan & 32 & $0 \%$ & $59.4 \%$ \\
\hline Maran & 30 & $13.3 \%$ & $33.3 \%$ \\
\hline Temerloh & 30 & $10 \%$ & $66.6 \%$ \\
\hline total & 120 & $5.8 \%$ & $58.0 \%$ \\
\hline Overall & 384 & $6.5 \%$ & $51.8 \%$ \\
\hline
\end{tabular}


Table 3. Salmonella spp and E. coli susceptibility towards all antimicrobials tested.

\begin{tabular}{|c|c|c|c|c|c|c|}
\hline \multirow{2}{*}{ Antimicrobials } & \multicolumn{2}{|c|}{ Susceptible (\%) } & \multicolumn{2}{|c|}{ Intermediate (\%) } & \multicolumn{2}{|c|}{ Resistant (\%) } \\
\hline & Salmonella & E. coli & Salmonella & E. coli & Salmonella & E. col \\
\hline Tetracycline & 38 & 5.3 & 0 & 0 & 62 & 94.6 \\
\hline Chloramphenicol & 23.8 & 14.8 & 0 & 0.5 & 76.2 & 84.5 \\
\hline Ampicillin & 52.3 & 12 & 0 & 0.5 & 47.7 & 87.5 \\
\hline Streptomycin & 76.1 & 31 & 4.7 & 3 & 19 & 66 \\
\hline Gentamicin & 100 & 75.6 & 0 & 4.2 & 0 & 20.2 \\
\hline $\begin{array}{l}\text { Sulfamethoxazole/ } \\
\text { trimethoprim }\end{array}$ & 57.1 & 16 & 0 & 0.5 & 42.9 & 83.3 \\
\hline Nalidixic acid & 90.4 & 39.3 & 0 & 0 & 9.6 & 60.7 \\
\hline Kanamycin & 71.4 & 43 & 0 & 0 & 28.6 & 57 \\
\hline Erythromycin & 0 & 0 & 0 & 0 & 100 & 100 \\
\hline Ciprofloxacin & 95.2 & 72 & 0 & 4.2 & 4.8 & 23.8 \\
\hline Cephalothin & 100 & 87 & 0 & 2 & 0 & 11 \\
\hline Colistin sulphate & 100 & 100 & 0 & 0 & 0 & 0 \\
\hline
\end{tabular}

8

8


Table 5. Antimicrobial resistance patterns and multiple resistance index (MAR) in Salmonella spp. isolate

\begin{tabular}{|c|c|c|c|c|c|c|}
\hline \multirow{2}{*}{$\begin{array}{l}\text { No of } \\
\text { antimicrobials }\end{array}$} & \multicolumn{3}{|c|}{ Salmonella } & \multicolumn{3}{|l|}{ E. coli } \\
\hline & MDR profile & $\begin{array}{c}\% \text { of } \\
\text { isolates }\end{array}$ & MAR index & MDR profile & $\begin{array}{c}\% \text { of } \\
\text { isolates }\end{array}$ & MAR index \\
\hline 12 & $\mathrm{~N} / \mathrm{A}$ & $\mathrm{N} / \mathrm{A}$ & $\mathrm{N} / \mathrm{A}$ & $\mathrm{N} / \mathrm{A}$ & $\mathrm{N} / \mathrm{A}$ & $\mathrm{N} / \mathrm{A}$ \\
\hline 11 & $\mathrm{~N} / \mathrm{A}$ & $\mathrm{N} / \mathrm{A}$ & $\mathrm{N} / \mathrm{A}$ & $\begin{array}{l}\text { TE - C-AMP-S - CN- SXT- NA -K- E- CIP- } \\
\text { CL }\end{array}$ & 1.2 & 0.9 \\
\hline 10 & $\mathrm{~N} / \mathrm{A}$ & $\mathrm{N} / \mathrm{A}$ & $\mathrm{N} / \mathrm{A}$ & $\begin{array}{l}\text { TE - C-AMP-S - CN- SXT- NA -K- E- CIP } \\
\text { TE - C-S - CN- SXT- NA -K- E- CIP- CL } \\
\text { TE - C-AMP-S - CN- NA -K- E- CIP- CL }\end{array}$ & 5.9 & 0.8 \\
\hline 9 & $\mathrm{~N} / \mathrm{A}$ & $\mathrm{N} / \mathrm{A}$ & $\mathrm{N} / \mathrm{A}$ & $\begin{array}{l}\text { TE - C-AMP-S - CN- SXT- NA -K- E } \\
\text { TE - C-AMP-S -SXT- NA -K- E- CIP } \\
\text { TE - C-AMP-S - SXT- K- E- CIP- CL } \\
\text { TE - C-AMP-S - NA -K- E- CIP- CL } \\
\text { C-AMP-S - CN- SXT- NA -K- E- CIP } \\
\text { TE - C-AMP-S - CN- SXT- NA -E- CIP }\end{array}$ & 10.7 & 0.7 \\
\hline 8 & $\begin{array}{l}\text { TE- C- AMP - S- SXT - K - } \\
\text { E- CIP }\end{array}$ & 4.8 & 0.7 & $\begin{array}{l}\text { TE - C-AMP-S - CN- SXT- E- CL } \\
\text { TE - C-AMP-S - SXT- NA -K- E } \\
\text { TE - C-AMP- S- SXT- NA -K- E } \\
\text { TE - C-AMP-S - CN- SXT- K- E } \\
\text { TE - C-AMP-S - CN- SXT- K- E } \\
\text { TE - C-AMP-S - NA - K- E- CIP } \\
\text { TE - C-AMP-S - CN- NA -K- E } \\
\text { TE - AMP-S - CN- SXT- NA -K- E }\end{array}$ & 21.4 & 0.6 \\
\hline 7 & TE - C - S- SXT - NA - K - E & 4.8 & 0.6 & $\begin{array}{l}\text { TE - C-AMP-S -SXT- NA -E } \\
\text { TE - C-AMP- SXT- NA -K- E } \\
\text { TE -AMP-S - SXT- NA -K- E } \\
\text { TE - C-S -SXT- NA -K- E } \\
\text { TE -AMP-S - SXT- NA -K- E } \\
\text { TE - C-AMP- CN- SXT-K- E } \\
\text { TE - C-AMP-S - SXT-K- E } \\
\text { TE - C-SXT- NA -K- E- CIP } \\
\text { TE - C-AMP -SXT- NA - E- CIP }\end{array}$ & 20.2 & 0.5 \\
\hline
\end{tabular}

20




\begin{tabular}{|c|c|c|c|c|c|c|}
\hline & & & & TE - C-AMP- NA - E- CIP- CL & & \\
\hline 6 & TE - C - AMP - S - SXT - E & 4.8 & 0.5 & $\begin{array}{l}\text { TE - C-AMP- SXT- K- E } \\
\text { TE - C-AMP-S - SXT- E } \\
\text { TE - C-SXT- NA -E- CIP } \\
\text { TE - C-AMP- SXT- NA - E } \\
\text { TE -AMP-SXT- NA-K- E } \\
\text { TE - C-AMP-NA - E- CIP } \\
\text { TE -S - CN- SXT- K- E }\end{array}$ & 17.2 & 0.5 \\
\hline 5 & $\begin{array}{l}\text { S - SXT - NA - K - E } \\
\text { TE - C - AMP - K - E }\end{array}$ & 14.2 & 0.4 & $\begin{array}{l}\text { TE - C-AMP-SXT- E } \\
\text { TE - C- S - SXT-E } \\
\text { TE - C-AMP- K- E } \\
\text { AMP-NA - E- CIP- CL } \\
\text { TE -AMP-SXT- NA - E } \\
\text { TE -AMP-SXT- K- E } \\
\text { TE -AMP-S - SXT-E } \\
\text { TE -AMP-NA - E- CIP } \\
\text { C-AMP-SXT- K- E } \\
\text { TE - AMP-S- NA - E }\end{array}$ & 12.5 & 0.4 \\
\hline 4 & $\begin{array}{l}\text { TE - C - AMP - E } \\
\text { TE - C - SXT - E } \\
C-A M P-K-E \\
C-A M P-S X T-E\end{array}$ & 42.8 & 0.3 & $\begin{array}{l}\text { TE - S - SXT- E } \\
\text { TE - C-AM- E } \\
\text { C-AMP-SXT-E } \\
\text { TE -AMP-SXT-E } \\
\text { TE -AMP-E- CL } \\
\text { AMP-K- E- CL } \\
\text { TE - C- SXT-E }\end{array}$ & 6.5 & 0.3 \\
\hline 3 & $\begin{array}{l}\text { SXT - C - E } \\
\text { TE - C - E }\end{array}$ & $(9.5$ & 0.2 & $\begin{array}{l}\text { TE - AMP- E } \\
S-N A-E \\
T E-C-E\end{array}$ & 3.5 & 0.2 \\
\hline 2 & $\mathrm{~N} / \mathrm{A}$ & $\mathrm{N} / \mathrm{A}$ & $\mathrm{N} / \mathrm{A}$ & AMP-E & 0.5 & 0.1 \\
\hline 1 & $E$ & 19 & 0.08 & $\mathrm{~N} / \mathrm{A}$ & 0 & 0 \\
\hline
\end{tabular}

TE, tetracycline; C, chloramphenicol; AMP, ampicillin; CL, cephalothin; S, streptomycin; CN, gentamicin; SXT, sulfamethoxazole/trimethoprim; NA,

nalidixic acid; CIP, ciprofloxacin; E, erythromycin; K, kanamycin 